DOI: 10.1515/ausp-2015-0050

\title{
Developing Evaluation Skills with Legal Translation Trainees
}

\author{
Titela VÎLCEANU \\ University of Craiova \\ Department of British, American and German Studies, Craiova \\ elavilceanu@yahoo.com
}

\begin{abstract}
Axiomatically, translation is twofold: an activity/process (more accurately designated by the term translating) and a product (the term translation can be restricted to the product). It seems that the product dimension has gained increased importance, being the most visible part of translation as market-driven, design-oriented, precise and measurable - complying with specifications. Translation engenders a sequence: identification of text type and of end users' needs (experts or non-experts in the field), evaluation of the complexity of the source text via global reading, followed by a close reading of its parts, the translating of the document, the translator's checking of final version, editing and proofreading. The translator's choices are accountable in point of cost-effectiveness (efficiency) and effectiveness. Therefore, the legal translator should master the methodological toolkit, conceptual frame and related terminology, and adopt an inward-looking perspective (intuition, subjectivity, ingrained habits, insights deriving from his/her expertise and experience) alongside an outward-looking one (working against objective criteria, standards of quality, benchmarks, etc).
\end{abstract}

Keywords: legal translation, evaluation skills, cost-effectiveness

\section{The rhetoric of translation evaluation}

The overall purpose of translation evaluation, in general, and of developing evaluation skills with legal translation trainees, in particular, is that to further raise awareness of the rule-governed nature of the translation process (the text as a self-contained entity, structured internally, alongside controlling socio-cultural variables) and identify regularities of behaviour so as to benchmark without being premised by simplifying assumptions that may hinder rewarding outcomes.

In an attempt to map translation evaluation to Optimality theory, we may state that translation as a rule-governed process and a product of linguistic and socio-cultural behaviour is cost-effective or optimal with respect to the degree of 
compliance with a set of criteria specified for a certain task. To put it crudely, there is need to decode (in the source language) and encode (in the target language) a given message completely and coherently.

Reading and (re)writing in the language industry, i.e. for translational purposes, is based on "an attitude of knowledge-based receptivity" (Stolze in Hansen, G., Malmkjær, K., Gile, D. 2004: 41) allowing the translator an expert holistic positioning of the text in the host culture (be it symmetrical or not to the one in the home culture), discourse field, and conceptual frame.

Undoubtedly, translation evaluation is ideologically and axiologically loaded - in this respect, we favour a multidisciplinary pattern underpinning linguistics, pragmatics, intercultural communication, cognitive sciences, ${ }^{1}$ and the ethics of translation and of translation evaluation, in particular.

\section{Ongoing dichotomies and beyond}

Translation is both enactment/process (customarily designated by the term translating) and a product (the term translation as restricted to the product). It seems that the product dimension has gained increased importance, being the most visible part of translation as design-oriented, precise, and measurable complying with specifications.

Basically, translation is performed by taking into account the readership's/ client's expectations (skopos) and the text type (observance of stylistical conventions); in fact, we should be aware of a nexus of relationships, of interconnnectedness, and postulate the dialectical nature of the relationship that the translators built and maintain with the market. Translation is stepwise, engendering a sequence:

- identification of text type and of end users' needs (experts or non-experts in the field),

- evaluation of the complexity of the material to be translated by a global reading,

- followed by a close reading of its parts,

- the translating of the document,

- the translator's checking of the final version - "the editorial process through the looking-glass" in Gile and Hansen's words (Gile and Hansen 2004: 297), and

- proofreading.

1 "As a result of constant selection pressure towards increasing efficiency, the human cognitive system has developed in such a way that our perceptual mechanisms tend automatically to pick out potentially relevant stimuli, our memory retrieval mechanisms tend automatically to activate potentially relevant assumptions, and our inferential mechanisms tend spontaneously to process them in the most productive way" (Wilson and Sperber 2002a: 254). 
The text type and the clients' needs weigh heavily in the choice of the translation strategy, namely reader-oriented/communicative or author-centred/ semantic translation (Newmark 1988), and the translator's agency, even if the degree of visibility is not easily detectable, should not be undermined:

Human action is intentional, but determinate, self-reflexively measured against social rules and resources, the heterogeneity of which allows for the possibility of change with every self-reflexive action (Venuti 1996: 206). The professional translator is not solely a practitioner adopting an empirical approach. S/he has also acquired theoretical knowledge of the framework of translation, i.e. there is an expected degree of routinization, awareness of recurrent problems and of a set of recontextualizable etic models (which we would like to call reusables). We assimilate this to situation monitoring in opposition with situation management when the translator deals with highly specific problems with reference to a particular text, and s/he needs to evaluate them as different from the ones pertaining to the global framework, and for which s/he should be able to provide emic solutions. ${ }^{2}$ More often than not, the solutions to these particular problems may derive by using recontextualization strategies, accountable in point of costeffectiveness (efficiency) and effectiveness. To our mind, such interdependencies were clearly identified within the Polysystem theory ${ }^{3}$ (originally concerned with literary translation), but they equally apply to specialized translation.

The legal translator should master the conceptual frame, the methodological toolkit, and related terminology. During training sessions, trainees come to understand that it is essential for the translator to allot time to editing and to proofreading (by another set of fresh eyes) and revising the translation, focusing on doubtful points.

The inward-looking perspective of the translator is to be accompanied by the outward-looking one (objective criteria), thus securing referential accuracy, naturalness of the target-language text, internal and external coherence (consistent use of terminology throughout all the translated documents), efficient use of the available resources, ability to benchmark and appreciate best practices, and, last but not least, a reflective approach to the ongoing work/project and the completed one.

Furthermore, there is need to mention that the trainees have become familiarized with the new European standard EN 15038 regulating the requirements for translation services (effective since August 2006).

2 The etic perspective is concerned with generalizations or universal laws, whereas the emic approach is related to (highly) specific features.

3

„... it suffices to recognize that it is the interdependencies between these factors which allow them to function in the first place. Thus, a CONSUMER may "consume" a PRODUCT produced by a PRODUCER, but in order for the "product" (such as "text") to be generated, a common REPERTOIRE must exist, whose usability is determined by some INSTITUTION. A MARKET must exist where such a good can be transmitted. None of the factors enumerated can be described to function in isolation, and the kind of relations 
Hence, strict polarized dichotomies should be abandoned, crediting translation as an instance of communication embedded within a given situation and within a broader socio-cultural context. Furthermore, translation evaluators should achieve consilience or unity of knowledge (the term is transplanted from biology - Wilson 1998) in order to balance subjective views and objective requirements and to decide on the quality label they attach to the deliverable/delivered product.

\section{Methodological scenario}

The proposed methodological toolkit follows Dieng-Kuntz's (qtd by Schwartz 2006: $101 \mathrm{ff}$.) method of construction of a corporate semantic Web, accommodating it to legal translation evaluation requirements.

In what follows, we shall exemplify by a workshop (translation project simulation) with trainees belonging to the Master's programme English and French Languages. European Legal Translation and Terminology, University of Craiova, $1^{\text {st }}$-year students, sample population: 24 members.

The main objective of the workshop was to familiarize students with the workflow of a translation project beyond theoretical grounding, i.e. from a handson perspective.

From the viewpoint of workshop management, we divided the students into groups of 6, assigning them different roles: the translator ${ }^{4}$ (undertaking selfrevision), the terminologist (in charge with terminology search and management), the proofreader (mostly concerned with the linguistic level), the monolingual expert in the field (involved in the unilingual reading of the target text) (all of them acting as knowledge holders), the end user and the annotator, i.e. the mediator in charge with building the documentation centre to be made available to all the members of the group and of the other groups.

The workshop was held in the multimedia laboratory, ensuring all the related logistics (monolingual and bilingual legal dictionaries - paperback copies, included).

Stage 1: Inventory of fixtures: we include here source- and target-language texts, and available technology. More specifically, we selected the source text:

Multiple framework service contract (retrievable from http://ec.europa. eu/enterprise/newsroom/cf/_getdocument.cfm?doc_id=4225) and the target text: Model-contract cadru multiplu prestari servicii as the official translation (retrievable from http://cor.europa.eu/en/about/tenders/calls/Documents/ ContractModelECDR-DE-56-2013/RO.pdf).

that may be detected run across all possible axes of the scheme" (Even-Zohar 1990: 34).

4 Although the translated text to be evaluated is the official version provided by EC, we still assigned this role so as to raise awareness of the translator's profile and accountability. 


\section{Stage 2: Choice of application scenario:}

- user-aimed and application-aimed - profiling intended users: experts in the field, dealing with such contracts on a regular basis, and learning or working environments: trainees, professional translators, trainers, other stakeholders;

- information sources - translator's expertise, available dictionaries, glossaries, memory systems, or other databases. Prior to the organization of the workshop, students had been already familiarized with the translation, terminology, and drafting resources provided by The Directorate-General for Translation (DGT), European Commission, namely:

- How to write clearly: with a view to achieving a natural, ,simple, uncluttered style,” avoiding translation pitfalls such as „false friends, jargon, and abbreviations" (please visit: http://ec.europa.eu/ipg/basics/ management/day_to_day/dgt/index_en.htm);

- the in-house English style guide: concerned not only with stylistic and functional aspects but also with developing basic knowledge of the EU structure, legislation (primary and secondary), institutions, official publications, etc. (please, visit: http://ec.europa.eu/translation/english/ guidelines/documents/styleguide_english_dgt_en.pdf);

- the Interinstitutional style guide: mainly establishing a frame of reference for drafting documents in the other languages of the European portfolio (please, visit: http://publications.europa.eu/code/en/en-000300.htm);

- IATE - The EU's multilingual term base: containing more than 8 million terms in all official EU languages and covering a broad variety of domains, which we consider extremely useful in the painstaking endeavour to standardize European legal terminology, providing equivalents rather than correspondents as overtly shown in its policy statement „Find a foreignlanguage equivalent of a term in the institutions' official term database" (please, visit: http://iate.europa.eu).

- Translation and drafting resources: providing, inter alia, a glossary of Romanian legal terms (please visit http://www.csm1909.ro/csm/ linkuri/08_08_2008_16613_ro.pdf); a body of Romanian laws (so that the translators may get accustomed to the specificities of the legal discourse in Romanian; please, visit: http://www.lege-online.ro/portal-legislatie, http:// www.lege-online.ro/portal-legislatie, http://www.legex.ro/); free access to PROZ - the translators' forum (please, visit: http://www.proz.com/search), etc.; EUR-Lex - providing direct access to the European Union law in all the official languages as well as extensive search facilities, acting as a reference centre or benchmark (please, visit: http://eur-lex.europa.eu/).

- contents and grain of the ontology - categories to deal with and related properties: legal language - service contract, translation evaluation. 
Stage 3: Construction of the ontologies: deciding on the conceptual vocabulary of the communities of practice (concepts and related definitions, conceptual networks, partonomy of concepts, i.e. hierarchical structures, cumulatively representing shared knowledge or common ground). This conceptual modelling derives

- from human sources - participants and their status roles; in our case, the trainees learnt how to share knowledge and accept criticism;

- from textual corpus - the workshop laid the foundation bricks of a corpusbased model of legal translation evaluation;

- from structured databases.

Our focus was twofold: on the one hand, the students had to become familiar with the key vocabulary and textual patterning associated with Multiple framework service contract/ Model-contract cadru multiplu prestari servicii. In this respect, we envisaged the isomorphism of the English and Romanian texts in point of richly modified noun phrases, of Present Simple Tense, Passive Voice, impersonal constructions, use of acronyms, vagueness: reasonably/rezonabil, all the necessary steps - toate măsurile necesare; nevertheless, there are instances of anisomorphism, such as the (over)use of the modal verb shall in English, which was rendered in most of the instances by the verbal phrase are obligația să (indicating obligation). On the other hand, we paid close attention to the metalanguage of translation quality assurance and quality control. More specifically, we aimed at developing the trainees' ability to report (identify, categorize, and correct) errors according to their seriousness and frequency; ${ }^{5}$ to document errors from a longterm/lifelong learning perspective (reference was constantly made to the quality standard EN 15038, effective since August 2006); to assimilate specific job profiles (see division of labour in the group work); to assimilate and use legal translation evaluation criteria (level of naturalness/language authenticity; internal and external coherence/consistent use of terminology; compliance with translation ideology, i.e. the translator's divided loyalties to the source text and target text or tailoring the translation to accommodate to the readership's expectations/client's specifications; correct usage and referential accuracy).

\section{Stage 4: Validation of the ontologies:}

- consistency checking from system viewpoint - examination of thematic files (collections of legal documents on specific fields of EU activity);

- knowledge audit and validation by experts - definitely, the reference texts are official versions approved by EU management authorities; besides, the

$5 \quad$ For the sake of quantification, the degree of seriousness of an error is jointly determined by the extent to which it impedes carrying the message across and by the amount of (cognitive) effort required for remedial work. Hence, they fall into major and minor errors. We also classify errors according to language areas: grammatical errors, lexical errors, and pragmatic errors (registerrelated, field related, etc.). 
trainer's expertise counts as knowledge audit alongside other knowledge holders' evaluation of the product;

- evaluation by end-users - the follow-up of the workshop involved case studies presented by mainstream literature or arising during trainees' internships.

Stage 5: Constitution, organization and validation of resources - accepting granularity (entire documents or relevant parts of the documents):

- new resources created: the added value is related to the drawing up of a final legal translation evaluation report and the creation and organization of a legal translation evaluation database;

- legacy resources adapted (transformed, re-organized, transferrable) - general translation evaluation criteria are adapted to legal translation evaluation.

Stage 6: Annotation of Resources - this indexing is aimed to secure compatibility with the work environment:

- manual annotation;

- automatic annotation;

- semi-automatic annotation.

Starting with Stage 7, the cycle curves upon itself via the repetition of stages 1-6. We mention that, in our case, stages 7-8 represent future collective projects.

\section{Stage 7: Validation of the annotations and of the newly created databases}

- consistency checking from system viewpoint;

- knowledge audit and validation by experts;

- evaluation by end-users.

Stage 8: Maintenance and dynamic evolution of the newly created databases so as to allow end-users to retrieve, disseminate, and exploit resources cascading in a proactive way, and enabling co-operation:

- ontologies;

- resources;

- annotations. 


\section{Conclusions}

In a pedagogical approach that builds legal translation evaluation competence, incrementally with the trainees' active participation and constructivist stance, emphasis should be placed on maximizing their autonomy, providing them with a viable methodological toolkit, clearly identified (achievable) goals, and a choice of paths to follow. Admittedly, the above mentioned methodological scenario is collaborative and learner-centred, valuing the trainees' contribution and capitalizing both trainer's and trainees' knowledge.

\section{References}

Even-Zohar, I. 1990. Poetics today 11 (1). Special Issue "Polysystem Studies". Hansen, G.-Malmkjær, K.-Gile, D. 2004. Claims, changes and challenges in translation studies. Amsterdam: John Benjamins Publishing Company.

Newmark, P. 1988. A textbook of translation. London: Prentice Hall International. Stolze, R. 2004. Creating 'presence' in translation. In: Hansen, G., Malmkjær, K., Gile, D. (eds), Claims, changes and challenges in translation studies. Amsterdam: John Benjamins Publishing Company, pp. 39-51.

Schwartz, D. G. 2006. Encyclopedia of knowledge management. Hershey London: Idea Group Reference.

Venuti, L. 1996. Translation as a social practice: or, the violence of translation. Translation Perspectives IX: 195-213.

Wilson, E. 1998. Consilience. The unity of knowledge. New York: Vintage Books.

\section{Websites}

Source text: Multiple framework service contract-http://ec.europa.eu/enterprise/ newsroom/cf/_getdocument.cfm?doc_id=4225 (downloaded on 05.05.2014)

Target text: Model-contract cadru multiplu prestari servicii - http://cor.europa. eu/en/about/tenders/calls/Documents/ContractModelECDR-DE-56-2013/ RO.pdf (downloaded on 05.05.2014)

http://ec.europa.eu/ipg/basics/management/day_to_day/dgt/index_en.htm http://ec.europa.eu/translation/english/guidelines/documents/styleguide english_dgt_en.pdf

http://eur-lex.europa.eu

http://iate.europa.eu

http://publications.europa.eu/code/en/en-000300.htm

(downloaded on 20.09.2014) 
http://www.csm1909.ro/csm/linkuri/08_08_2008_16613_ro.pdf http://www.lege-online.ro/portal-legislatie, http://www.lege-online.ro/portallegislatie

http://www.legex.ro/

http://www.proz.com/search 